\title{
The Role of Exogenous Hydrogen Sulfide in Free Fatty Acids Induced Inflammation in Macrophages
}

\author{
Zhu-lin Luo Jian-dong Ren ${ }^{\mathrm{b}}$ Zhu Huang ${ }^{\mathrm{a}}$ Tao Wang ${ }^{\mathrm{a}}$ Ke Xiang $^{\mathrm{a}} \quad$ Long Cheng $^{\mathrm{a}}$ \\ Li-jun Tang ${ }^{a}$
}

aDepartment of General Surgery, Chengdu Military General Hospital, Chengdu, bDepartment of Pharmacy, Chengdu Military General Hospital, Chengdu, China

\section{Key Words}

Exogenous Hydrogen Sulfide • Free Fatty Acids • Inflammation • Macrophages

\begin{abstract}
Background: This study aimed to investigate whether exogenous hydrogen sulfide $\left(\mathrm{H}_{2} \mathrm{~S}\right)$ can protect the RAW264.7 macrophages against the inflammation induced by free fatty acids (FFA) by blunting NLRP3 inflammasome activation via a specific TLR4/NF-KB pathway. Methods: RAW264.7 macrophages were exposed to increasing concentrations of FFA for up to 3 days to induce FFA-induced inflammation. The cells were pretreated with NaHS (a donor of $\mathrm{H}_{2} \mathrm{~S}$ ) before exposure to FFA. Cell viability, cell apoptosis, TLR4, NF-KB, NLRP3 inflammasome, IL$1 \beta, I L-18$ and cleaved caspase- 3 expression were measured by a combination of MTT assay, ELISA, and immunoblotting. Results: $\mathrm{H}_{2} \mathrm{~S}$ attenuated FFA-induced cell apoptosis, and reduced the expression of NLRP3, ASC, pro-caspase-1, caspase-1, IL- $1 \beta$, IL-18 and caspase-3. In addition, $\mathrm{H}_{2} \mathrm{~S}$ inhibited the FFA-induced activation of TLR4 and NF-KB. Furthermore, NLRP3 inflammasome activation was regulated by the TLR4 and NF-KB pathway. Conclusion: The present study demonstrated for the first time that $\mathrm{H}_{2} \mathrm{~S}$ appears to suppress FFA-induced macrophage inflammation and apoptosis by inhibiting the TLR4/ NF-KB pathway and its downstream NLRP3 inflammasome activation. Thus $\mathrm{H}_{2} \mathrm{~S}$ might possess potential in the treatment of diseases resulting from FFA overload like insulin resistance and type diabetes.
\end{abstract}

(C) 2017 The Author(s)

Published by S. Karger AG, Basel

\section{Introduction}

The ongoing global epidemic of metabolic syndrome and obesity has generated renewed interest on the mechanisms by which metabolic overload driven increase in circulating free fatty acids impinge on the chronic inflammatory pathways within the immune microenvironment [1]. It is however well appreciated that this inflammation is central to development of insulin resistance [1-3]. "Metainflammation" refers to the unresolved chronic inflammation as a result of interplay between macrophages and adipocytes [4].

Z.-I. Luo, J.-d. Ren and Z. Huang contributed equally to this work.

Dr. Li-jun Tang and Dr. Jian-dong Ren

KARGER
Department of General Surgery, Chengdu Military General Hospital No.270, Tianhui Road, Chengdu, Sichuan 610083, (China) and Department of Pharmacy, Chengdu Military General Hospital, No.270, Tianhui Road, Chengdu, Sichuan 610083, (China); E-Mail lijuntang_med@126.com / keanrjd@126.com 
Metainflammation is reliant on the C-C chemokine receptor type 5 (CCR5) and CCR2 signaling [5-9]. Fatty acids were shown to induce inflammation in the extracellular milieu by activating toll-like receptor (TLR) signaling, inclusive of TLR4, TLR2, and subsequently promoting its dimerization with TLR6 or TLR1 [10-13]. Fatty acids have also been shown to induce inflammation in primary human macrophages [14].

An important regulator of inflammation associated with metabolic syndrome is the nucleotide-binding domain, leucine-rich-containing family, pyrin domaincontaining-3 (NLRP3) inflammasome, which consists of caspase-1 and apoptosis-associated specklike protein containing a caspase recruitment domain (ASC) [15]. In fact, induction of phosphorylation of the p65 subunit of NF- $\kappa$ B resulting in NF- $\kappa B$ signaling activation is prerequisite for transcriptional activation of NLPR3 [15]. Cleavage, processing and secretion of pro-inflammatory cytokines IL- $1 \beta$ and IL-18 result from NF- $\kappa B$-mediated activation of NLRP3 inflammasome and subsequent caspase-1 activation [16]. It is however unknown if the TLR4-NF- $\kappa B-N L R P 3$ pathway is involved in free fatty acid-induced inflammatory response within resident macrophages.

Hydrogen sulfide $\left(\mathrm{H}_{2} \mathrm{~S}\right)$, synthesized from cysteine by cystathionine gamma lyase (CSE), along with nitric oxide (NO) and carbon monoxide (CO) form the group of biologically active gasomediators or gasotransmitters, and participates in both pro- and anti-inflammatory signaling [17-20]. $\mathrm{H}_{2} \mathrm{~S}$ has been shown to be a modulator of leukocyte-mediated inflammatory responses [21] and its synthesis increases during pro-inflammatory conditions [22]. The objective of the current study was to investigate if exogenous $\mathrm{H}_{2} \mathrm{~S}$ exhibits protection against free fatty acid (FFA)-induced inflammation and the underlying mechanism(s) dictating such observations.

\section{Materials and Methods}

This study was approved by the Institutional Review Board at Chengdu Military General Hospital.

\section{Cell culture}

The mouse macrophage cell line RAW264.7 (ATCC, Manassas, VA, USA) was maintained at $37^{\circ} \mathrm{C}$ in $\mathrm{a} \mathrm{CO}_{2}$ incubator. Complete RPMI medium (ThermoFisher Scientific, Shanghai, China) supplemented with $10 \%$ fetal bovine serum and penicillin $(100 \mathrm{U} / \mathrm{ml}) /$ streptomycin $(100 \mu \mathrm{g} / \mathrm{ml})$ (ThermoFisher Scientific) was used as the culture medium.

\section{Treatment}

Where indicated, cells were treated with palmitic (C16:0) (P0500) and oleic acid (C18:1) (01008) (Sigma Aldrich, Beijing, China). 0.1 M stock solutions were prepared by dissolving the respective free fatty acid (FFA) in DMSO. Control cells were treated with a similar concentration (v/v) of DMSO vehicle control. Cells were exposed for indicated times with increasing concentrations of a fresh mixture of exogenous FFA in a molar ratio of 1:2 palmitic:oleic acid. The major portion of FFA in the blood is carried in association with blood as FFA by itself is highly insoluble in the aqueous phase. Hence, serum levels of FFA are classically determined and dictated by the total serum FFA to total serum albumin. In the current study, FFA was complexed at a 4:1 molar ratio with bovine serum albumin (BSA) in accordance with the preexisting albumin concentration in the cell culture media due to FBS supplementation.

To explore the protective effect of $\mathrm{H}_{2} \mathrm{~S}$ on the FFA-induced inflammatory response, cells were pretreated with $400 \mu \mathrm{M}$ sodium hydrosulfide (NaHS) (Sigma Aldrich) for 30 minutes prior to FFA treatment [23-25]. To confirm the role of TLR4, cells were treated with $5 \mu$ M TAK-242 (inhibitor of TLR4) (ThermoFisher Scientific) along with FFA treatment.- To confirm the role of NF-kB, cells were pretreated with $10 \mu \mathrm{M}$ BAY11-7082 (inhibitor of NF-kB) (Sigma Aldrich) for 1 hour prior to FFA treatment.

RAW264.7 cells $\left(4 \times 10^{4} /\right.$ well $)$ were transiently transfected either with $50 \mathrm{nM}$ siRNA targeting NLRP3 (Ribo Biotechnology, Shanghai, China, sense, 5'-GCUUCAGCCACAUGACUUUTT -3', and antisense, 
5'-AAAGUCAUGUGGCUGAAGCTT - $3^{\prime}$ ), or a non-targeting siRNA scrambled control siRNA (sense, $5^{\prime}$-UUC UCC GAA CGU GUC ACG UTT-3', and antisense, 5'-ACG UGA CAC GUU CGG AGA ATT-3') using Lipofectamine LTX transfection reagent (ThermoFisher Scientific) as per the manufacturer's protocol. Twenty-four hours after transfections, cells were analyzed in indicated assays.

Cell proliferation assays

Cell proliferation was quantitated using a mitochondrial colorimetric assay (MTT assay, SigmaAldrich,) as per the manufacturer's recommendations. Results from three independent triplicates were expressed as mean $\pm \mathrm{SD}$.

ELISA for detection of $I L-1 \beta$ and $I L-18$ in culture supernatant

After indicated treatments, levels of IL-1 $\beta$ and IL-18 in culture supernatant were measured by ELISA (R\&D System, Minneapolis, MN, USA) according to the manufacturer's instruction. Results from ten independent triplicates were documented.

Protein extraction and western blotting

Protein was extracted from RAW264.7 cells with RIPA buffer, containing $50 \mathrm{mM}$ Tris- $\mathrm{HCl}$ (pH 7.4), 150 mM sodium chloride, $1 \%$ NP- $40,0.25 \%$ sodium deoxycholate, $1 \mathrm{mM}$ EDTA, $1 \%$ protease inhibitors cocktail (78425, Pierce, Rockford, IL, USA), 1 mM PMSF (36978, Pierce), 1 mM sodium orthovanadate (S6508, Sigma Aldrich) and $50 \mathrm{mM}$ sodium fluoride (S7920, Sigma Aldrich). Protein concentrations were determined using the BCA Protein Assay Kit (23227, Pierce). $40 \mu \mathrm{g}$ of total protein was resolved by SDS-PAGE. The blots were probed with primary antibodies against (TLR4 (\#ab13556) (1:2000), NLRP3 (\#ab214185) (1:1000), (both from Abcam, Cambridge, MA, USA), ASC (\#67824) (1:500), p-p65 (\#3033) (1:1000), totalp65 (\#8242) (1:1000), caspase-1 (\#2225) (1:1000), pro-caspase-1 (\#12242) (1:1000), cleaved caspase-3 (\#9661) (1:1000) or GAPDH (\#2118) (1:10000) (all from Cell Signaling Technology, Beverly, MA, USA).

\section{Statistical analysis}

Unless otherwise indicated, data was represented as means \pm standard error. Differences between groups were analyzed by one-way analysis of variance (ANOVA) with SPSS 16.0 (Chicago, IL, USA). A $P$ value $<0.05$ was considered as statistically significant.

\section{Results}

FFA induced apoptosis and inflammation in RAW264.7 cells

We initially investigated the effect of increasing concentrations of FFA on RAW264.7 macrophages after days 1,2, and 3. Determination of experimental doses was done by assessing cell viability in comparison to cells treated with equivalent concentration $(\mathrm{v} / \mathrm{v})$ of the DMSO vehicle. Cell viability was always higher than 50\% in FFA treated and $100 \%$ in DMSO treated cells. Significant decrease of cell viability was observed on all three days with 600 and $1000 \mu \mathrm{M}$ FFA, but not with $250 \mu \mathrm{M}$ FFA (Fig. $1 \mathrm{~A},{ }^{*} \mathrm{P}<0.05$; ${ }^{* *} \mathrm{P}<0.01$ ). Hence, 600 $\mu \mathrm{M}$ FFA was used for all subsequent experiments. The decrease in cell viability post-FFA treatment was consistent with an induction of the apoptosis marker cleaved caspase-3 (Fig. 1B).

Coincident with exacerbated apoptosis in FFA-treated RAW264.7 cells, ELISA revealed enhanced release of the pro-inflammatory cytokines in the culture supernatant. As shown in Fig. 1C and 1D, the levels of both IL-1 $\beta$ and IL-18 increased in culture supernatants of RAW264.7 cells treated with FFA for twenty four hours compared to corresponding culture supernatant treated with DMSO vehicle control $(\mathrm{P}<0.01)$. Of note, the inflammatory response as assessed by the cytokine levels in culture supernatants in the current scenario is rather a consequence of cell death than physiological secretion of cytokines in response to FFA. 


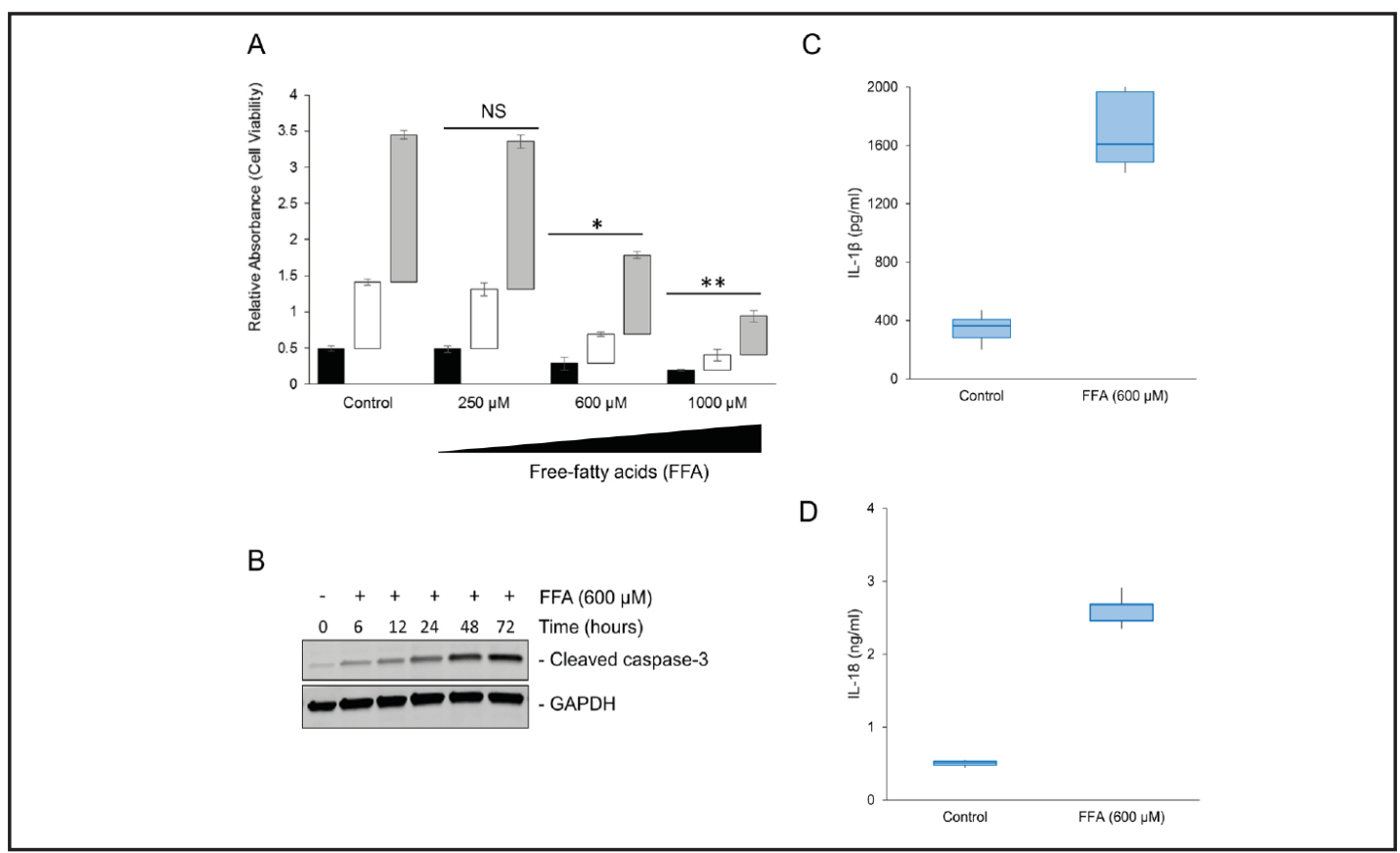

Fig. 1. FFA induced cell apoptosis and inflammation in RAW264.7 macrophages. RAW264.7 cells were treated with FFA at indicated concentrations or DMSO vehicle control at equivalent concentration (v/v). MTT assay was used for cell viability detection. (A). RAW264.7 cells were treated with $600 \mu \mathrm{M}$ FFA for indicated time frame, and then western blot analysis was performed to assess induction of the apoptosis marker, cleaved caspase-3. The blot was stripped and re-probed with GAPDH as a loading control. Experiment is representative of three independent experiments (B). RAW264.7 cells were cultured with $600 \mu \mathrm{M}$ FFA and protein levels of IL-1 $\beta$ (C) and IL-18 (D) were detected by ELISA. Data were presented as means \pm standard error, from 10 independent experiments. ${ }^{*} \mathrm{P}<0.05$ vs. control, ${ }^{* *} \mathrm{P}<0.01$ versus control.

Fig. 2. FFA induced expression of NLRP3 inflammasome, TLR4 and NF- $\kappa$ B in RAW264.7 cells. RAW264.7 cells were treated with $600 \mu \mathrm{M}$ FFA for indicated times. Western blot analyses were performed to assess indicated antigens including NLRP3 and TLR4 (A), and NF- $\mathrm{B}(\mathrm{B})$. The blots were stripped and re-probed with GAPDH as a loading control. Experiment is representative of three independent experiments.

\section{A}

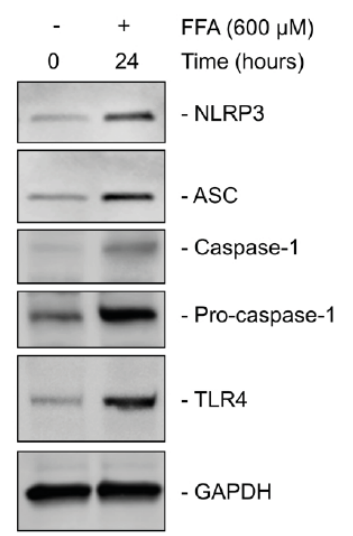

\section{B}

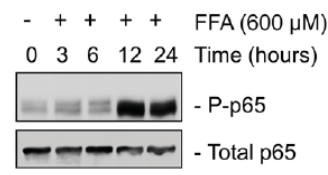

FFA induced inflammation showed concomitant increase in expression of the NLRP3 inflammasome, TLR4 and NF- $\kappa B$

NLRP3 inflammasome consists of three subunits, NLRP3, ASC and caspase-1, the later arising from pro-caspase-1. FFA treatment led to a robust increase in the expression of all three subunits (Fig. 2A), as well as the amount of pro-caspase-1 (Fig. 2A,). Likewise, two important intracellular signal pathways, TLR4 (Fig. 2A) and NF- $\kappa B$ (Fig. 2B), were both activated by FFA, the later within 12 hours of FFA treatment. The early induction of the NF$\kappa B$ signaling pathway is indicative that it might be central to the observed effects of FFA on inflammatory responses.

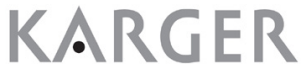




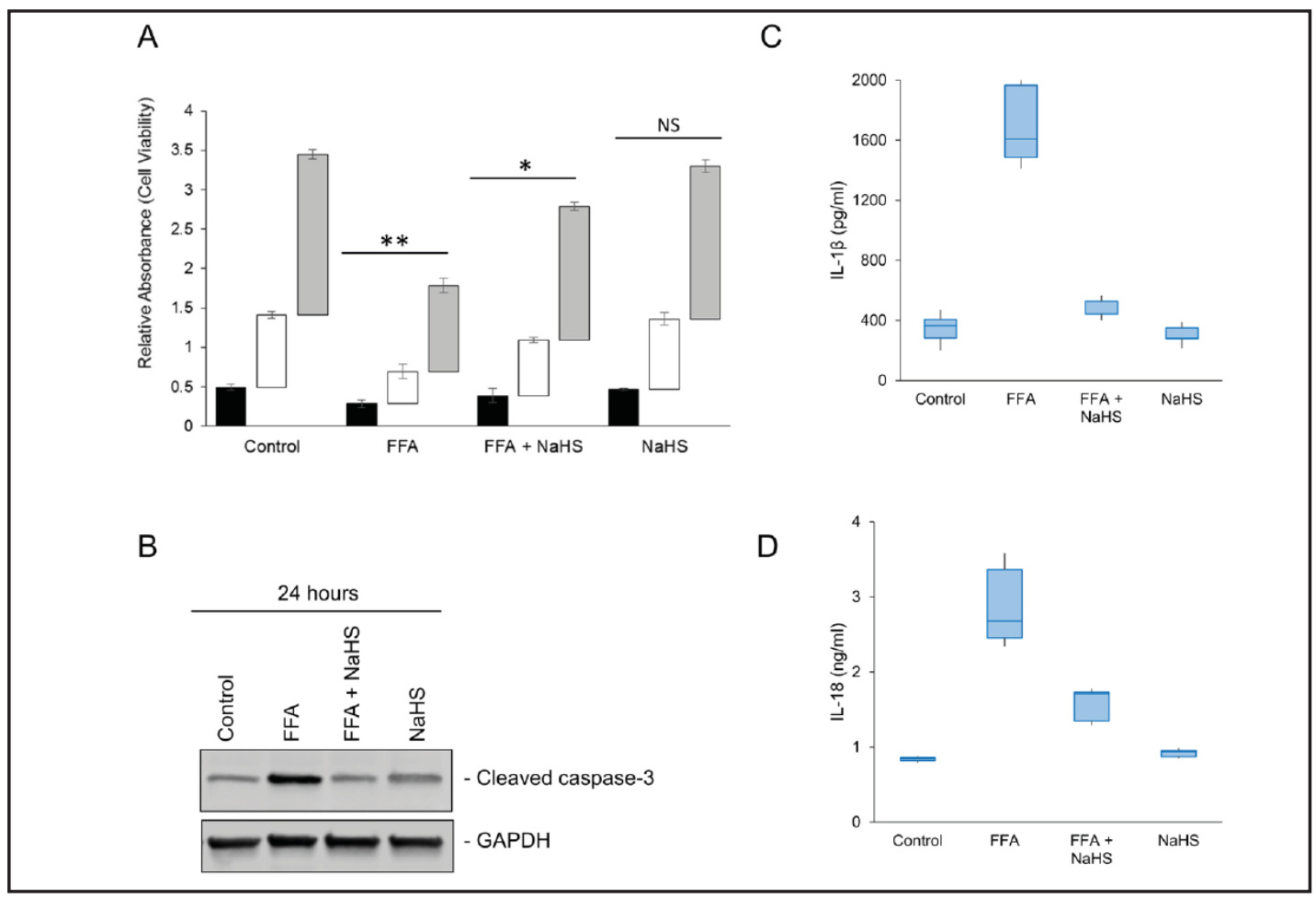

Fig. 3. FFA induced cell apoptosis and inflammation in RAW264.7 macrophages is attenuated by $\mathrm{H}_{2} \mathrm{~S}(\mathrm{NaHS})$ treatment. RAW264.7 cells were treated with FFA at indicated concentrations. In indicated cases, cells were pre-treated with $400 \mu \mathrm{M}$ NaHS for 30 minutes. MTT assay was used for cell viability detection (A). RAW264.7 cells were treated with $600 \mu \mathrm{M}$ FFA for indicated time frame. In indicated lanes, cells were pre-treated with $400 \mu \mathrm{M}$ NaHS for 30 minutes. Western blot analysis was performed to assess induction of cleaved caspase-3. The blot was stripped and re-probed with GAPDH as a loading control. Experiment is representative of three independent experiments (B). RAW264.7 cells were cultured with $600 \mu \mathrm{M}$ FFA for 24 hours \pm NaHS pre-treatment 30 minutes and protein levels of IL-1 $\beta$ (C) and IL-18 (D) were detected by ELISA. Data were presented as means \pm standard error, from 10 independent experiments. ${ }^{*} \mathrm{P}<0.05$ vs. control, ${ }^{* *} \mathrm{P}<0.01$ versus control.

\section{Exogenous H2S protected against FFA-induced apoptosis and inflammation}

We next investigated the effect of $\mathrm{H}_{2} \mathrm{~S}$ on FFA-induced injury. With pretreatment of NaHS for 30 minutes, cell viability was significantly increased compared to FFA-treated cells that were not pretreated with NaHS (Fig. $3 \mathrm{~A},{ }^{*} \mathrm{P}<0.05$; ${ }^{* *} \mathrm{P}<0.01$ ). In addition, the induction of the apoptosis marker cleaved caspase- 3 was reduced to levels observed in control cells (Fig. 3B). Furthermore, we examined the expression of pro-inflammatory cytokines in FFA + NaHS group. Pretreatment of RAW264.7 cells with NaHS significantly attenuated the release of both IL-1 $\beta$ and IL-18 in culture supernatants after twenty four hours compared to that observed in culture supernatant of cells treated with DMSO vehicle control (Fig. 3C, 3D).

In addition, the expression of NLRP3 inflammasome in the FFA + NaHS group was markedly reduced compared to the FFA group without no NaHS pre-treatment (Fig. 4A). The increase of TLR4 (Fig. 4A) and NF- $\kappa$ B (Fig. 4B) activation induced by FFA were also attenuated by NaHS. Treatment with NaHS alone did not have any effect on cell viability, apoptosis, or inflammasome (Fig. 3A-D, Fig. 4A, 4B).

Apoptosis and inflammation in FFA-treated macrophages is mediated by the NLRP3 inflammasome

To assess the role of the NLRP3 inflammasome in FFA-induced changes in cell viability and inflammasome we performed the assay in RAW264.7 transiently transfected either with a control non-targeting siRNA or siRNA directed against NLRP3. The protein level of NLRP3 KARGER 
Fig. 4. FFA-mediated induction of NLRP3 inflammasome, TLR4 and NF- $\kappa B$ in RAW264.7 cells is attenuated by $\mathrm{H}_{2} \mathrm{~S}$ (NaHS) treatment. RAW264.7 cells were treateded with $600 \mu \mathrm{M}$ FFA for 24 hours \pm NaHS pre-treatment for 30 minutes. Western blot analyses were used to assess protein levels of indicated antigens including NLRP3 and TLR4 (A), and NF- $\kappa B(B)$. The blots were stripped and re-probed with GAPDH as a loading control. Experiment is representative of three independent experiments.
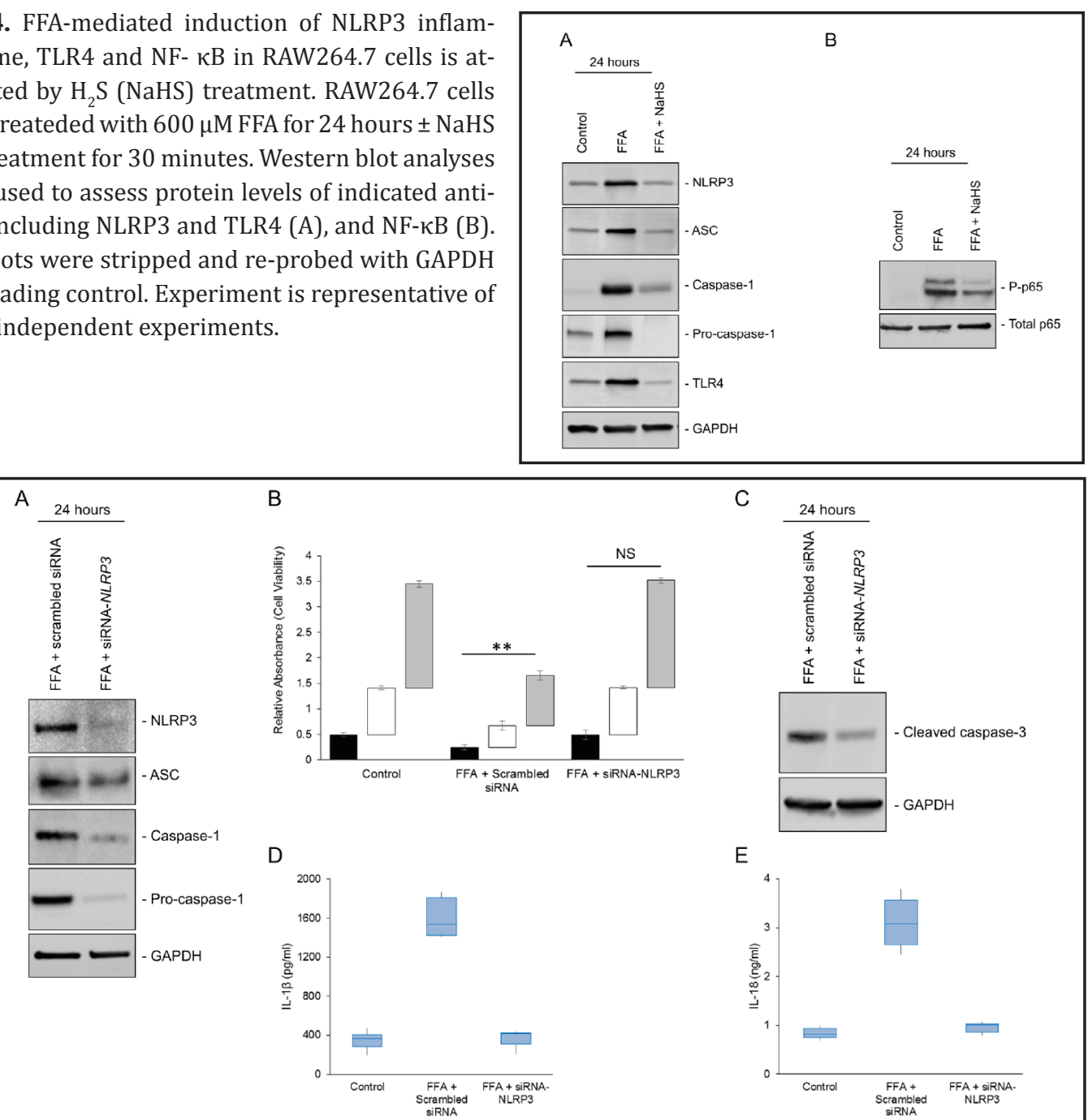

Fig. 5. Apoptosis and inflammation in FFA-treated macrophages is mediated by the NLRP3 inflammasome. RAW264.7 cells were cultured with $600 \mu \mathrm{M}$ FFA in cells transfected with either siRNA targeting NLRP3 or a non-silencing control [. Western blot analyses were used to assess protein levels of indicated antigens including subunits of the NLRP3 inflammasome, which showed NLRP3 gene silencing decreased the expression of ASC and caspase-1. The blots were stripped and re-probed with GAPDH as a loading control. Experiment is representative of three independent experiments (A). MTT assay was used for cell viability detection in the stated conditions (B). Western blot analysis was used to assess protein levels of cleaved caspase- 3 in the stated conditions. The blot was stripped and re-probed with anti-GAPDH antiboy t3 loading control. Experiment is representative of three independent experiments (C). RAW264.7 cells were cultured with $600 \mu \mathrm{M}$ FFA \pm siRNA-NLRP3 or control non-silencing siRNA and protein levels of IL-1 3 (D) and IL-18 (E) were detected by ELISA. Data were presented as means \pm standard error, from 10 independent experiments. ${ }^{*} \mathrm{P}<0.05$ vs. control, ${ }^{* *} \mathrm{P}<0.01$ versus control.

in RAW264.7 cells transfected with NLRP3-siRNA was significantly lower than the nontargeting siRNA control (Fig. $5 \mathrm{~A},{ }^{*} \mathrm{P}<0.05$; NS, not significant). The protein levels of activated ASC and caspase- 1 induced by FFA simultaneously decreased in the NLRP3-siRNA group compared with control siRNA group (Fig. 5A).

We then determined the contribution of NLRP3 to FFA-induced apoptosis. Silencing of NLRP3 resulted in significant rescue of cell viability in the FFA-treated cells (Fig. 5B), as well as decreased induction of the apoptosis marker cleaved caspase-3 (Fig. 5C) to levels similar 


\section{Cellular Physiology Cell Physiol Biochem 2017;42:1635-1644 \begin{tabular}{c|c|c|} 
DOI: 10.1159/000479405 & $\begin{array}{l}\text { O 2017 The Author(s). Published by S. Karger AG, Basel } \\
\text { www.karger.com/cpb }\end{array}$
\end{tabular}

Fig. 6. TLR4 and NF- $\kappa B$ induced NLRP3 inflammasome activation. Protein levels of p-p65 and total-p65 (A) and NLRP3 (B) in RAW264.7 cells treated as indicated were detected by western Blot analysis. Western blot analysis was used for protein levels of cleaved caspase- 3 in the stated conditions. The blot was stripped and re-probed with anti-GAPDH antibody to confirm loading control. Experiment is representative of three independent experiments.

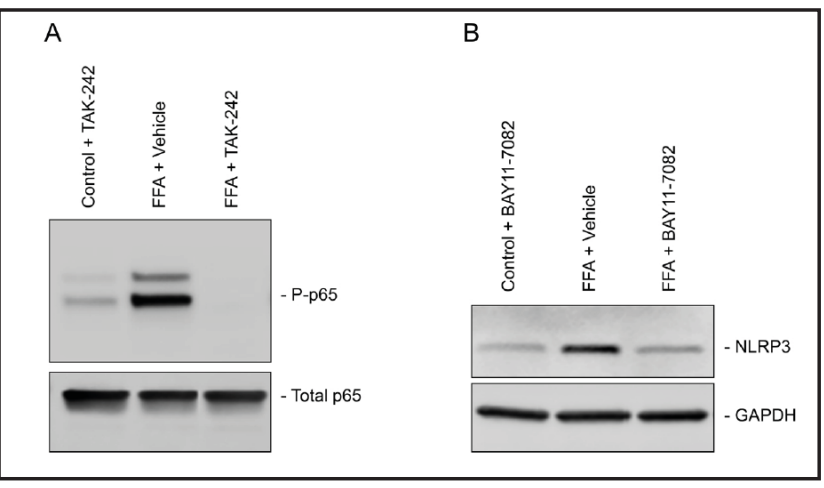

to observed in control cells (Fig. 1B). Expression of the pro-inflammatory cytokines IL-1 $\beta$ (Fig. 5D) and IL-18 (Fig. 5E) decreased to levels observed in control cells.

\section{TLR4 and NF- $K B$ mediated the FFA-induced NLRP3 inflammasome activation}

We next determined the association among TLR4, NF- $\kappa B$ and NLRP3 inflammasome. The protein level of phosphorylated NF- $\kappa$ B was decreased in FFA+TAK-242 group compared to the FFA + vehicle group (Fig. $6 \mathrm{~A}$ ). There was no robust difference in phosphorylated NF- $\kappa \mathrm{B}$ expression between TAK-242 group and control group (Fig. 6A).

Moreover, we inhibited the expression of NF- $\mathrm{B}$ by BAY11-7082, which specifically abrogates NF- $\kappa B$ DNA binding. Inhibition of NF- $\kappa B$ activation by BAY11-7082 decreased NLRP3 protein expression (Fig. 6B). Mo significant difference in phosphorylated NF- $\kappa B$ expression between TAK-242 group and control group was observed (Fig. 6A). Cumulatively, the data indicated that NF- $\mathrm{KB}$ is potentially inducing the NLRP3 inflammasome expression following FAA treatment.

\section{Discussion}

Our results presented here cumulatively demonstrate that FFAs can activate TLRmediated pro-inflammatory signaling pathways in macrophages (RAW264.7), which can be resolved by pretreatment with NaHS. H2S has been previously shown to resolve or attenuate inflammation in different inflammatory disorders like LPS-induced acute lung injury [26], glucose-induced cardiotoxicity [27], myocardial hypoxia-reoxygenation injury [28], and in neurodegenerative disorders like Parkinson's disease [29-31].

It has been previously shown that the inflammatory responsiveness of cells to FFAs is increased if cultured in low FBS concentration $(0.25 \%)$ compared with $10 \%$ FBS used in the current study [13]. This enhanced inflammatory response was shown to be dictated by enhanced reactive oxygen species production in the serum-starved conditions [13], which precludes that the inflammation we observed in the current study can be attributed to just the fatty acid treatment. Our results provide mechanistic insight about the activation of TLRand NF- $\kappa B$-derived signaling pathways induced by FFA and suggest that conditions that can modulate NLRP3 protein levels can affect the inflammatory responsiveness of cells to the FFA-based inflammatory stimuli.

Our data also showed that activation of NLRP3 inflammasome led to increased expression of IL-1 $\beta$ and IL-18 post-FFA treatment. Furthermore, NLRP3 silencing significantly attenuated the FFA-induced activation of IL-1 $\beta$ and IL-18, as well as cell death. It has been previously shown that high-fat diet (HFD) and inflammation are key contributors to insulin resistance and type 2 diabetes (T2D) [32]. It was shown that NLRP3-ASC inflammasome mediated IL-1 $\beta$ and IL-18 production involved the mitochondrial reactive oxygen species and the AMP-activated protein kinase and unc-51-like kinase-1 (ULK1) autophagy signaling cascade [32]. It has also been shown that the mitochondrial uncoupling protein 2 (UCP2) 
regulates the NLRP3 inflammasome by inducing the lipid synthesis pathway in macrophages [33] It will thus be important to determine the roles, if any, of ULK1 and UCP2 in the contextof FFA-induced NLRP3 inflammasome.

Endogenous FFAs are actually metabolic intermediates obtained through the diet or synthesized within the body [34]. Even though they do provide an important source of energy, they have detrimental effect especially when there is a FFA overload [34]. It seems that saturated fatty acids are more prone than unsaturated fatty acids in promoting NLRP3 inflammasome activation [34]. In our study we used a combination of unsaturated and saturated fatty acid, so a similar study with independent exogenous treatment with saturated and unsaturated fatty acid is warranted in the future.

Pretreatment of cells with the TLR4 inhibitor TAK-242 inhibits the production of lipopolysaccharide (LPS)-induced inflammatory mediator by binding to the intracellular domain of TLR4. Using the inhibitors of TLR4 and NF- $\kappa B$, we found that in FFA-treated k cells, inhibiting TLR4 signaling reduced the expression of NF- $\kappa \mathrm{B}$, while blocking NF- $\kappa B$ activation downregulated NLRP3 expression in FFA tread cells [35]. Furthermore, siRNA mediated silencing of TLR4 in monocytes led to decreased NF- $\kappa B$ activity and IL-1 $\beta$ release [35]. Moreover, NF- $\kappa B$ is known to increase expression of NLRP3 and IL-1 $\beta$; in fact NF- $\kappa B$ binding sites are present in the NLRP3 promoter [36, 37]. Cumulatively, NLRP3 inflammasome activation is thus a central outcome of TLR4/NF- $\mathrm{KB}$ stimulation in FFA-overload-mediated inflammation.

In conclusion, in the current work we show that exogenous $\mathrm{H}_{2} \mathrm{~S}$ can exert antiinflammatory effects against FFA-induced inflammation and apoptosis in macrophages by suppressing TLR4/ NF- $\kappa B$ stimulated NLRP3 inflammasome activation. $\mathrm{H}_{2} \mathrm{~S}$ can thus be a potential therapeutic agent to prevent FFA-overload-mediated insulin resistance and type 2 diabetes.

\section{Acknowledgements}

None.

\section{Disclosure Statement}

The authors declare that there is no conflict of interest regarding the publication of this paper.

\section{References}

1 McNelis JC, Olefsky JM: Macrophages, immunity, and metabolic disease. Immunity 2014;41:36-48.

-2 Samuel VT, Shulman GI: Mechanisms for insulin resistance: common threads and missing links. Cell 2012;148:852-871.

-3 Odegaard JI, Chawla A: Pleiotropic actions of insulin resistance and inflammation in metabolic homeostasis. Science 2013;339:172-177.

4 Gregor MF, Hotamisligil GS: Inflammatory mechanisms in obesity. Annu. Rev. Immunol 2011;29:415-445.

- 5 Xu H, Barnes GT, Yang Q Tan G, Yang D, Chou CJ, Sole J, Nichols A, Ross JS, Tartaglia LA, Chen H: Chronic inflammation in fat plays a crucial role in the development of obesity-related insulin resistance. J Clin Invest 2003;112:1821-1830.

-6 Weisberg SP, McCann D, Desai M, Rosenbaum M, Leibel RL, Ferrante AW Jr: Obesity is associated with macrophage accumulation in adipose tissue. J Clin Invest 2003;112:1796-1808.

7 Weisberg SP, Hunter D, Huber R, Lemieux J, Slaymaker S, Vaddi K, Charo I, Leibel RL, Ferrante AW Jr: CCR2 modulates inflammatory and metabolic effects of high-fat feeding. J Clin Invest 2006;116:115-124. 


\section{Cellular Physiology Cell Physiol Biochem 2017;42:1635-1644 \begin{tabular}{l|l} 
DOI: 10.1159/000479405 & $\begin{array}{l}\text { O 2017 The Author(s). Published by S. Karger AG, Basel } \\
\text { www.karger.com/cpb }\end{array}$ \\
\hline
\end{tabular}}

Luo et al.: $\mathrm{H}_{2} \mathrm{~S}$ in Fatty Acids Induced Inflammation

8 Keophiphath M, Rouault C, Divoux A, Clément K, Lacasa D: CCL5 promotes macrophage recruitment and survival in human adipose tissue. Arterioscler Thromb Vasc Biol 2010;30:39-45.

-9 Kitade H, Sawamoto K, Nagashimada M, Inoue H, Yamamoto Y, Sai Y, Takamura T, Yamamoto H, Miyamoto K, Ginsberg HN, Mukaida N, Kaneko S, Ota T: CCR5 plays a critical role in obesity-induced adipose tissue inflammation and insulin resistance by regulating both macrophage recruitment and M1/M2 status. Diabetes 2012;61:1680-1690.

$\checkmark 10$ Lee JY, Sohn KH, Rhee SH, Hwang D: Saturated fatty acids, but not unsaturated fatty acids, induce the expression of cyclooxygenase-2 mediated through Toll-like receptor 4. J Biol Chem 2001;276:1668316689.

-11 Shi H, Kokoeva MV, Inouye K, Tzameli I, Yin H, Flier JS: TLR4 links innate immunity and fatty acid-induced insulin resistance J Clin Invest 2006;116:3015-3025.

12 Lee JY, Zhao L, Youn HS, Weatherill AR, Tapping R, Feng L, Lee WH, Fitzgerald KA, Hwang DH: Saturated fatty acid activates but polyunsaturated fatty acid inhibits Toll-like receptor 2 dimerized with Toll-like receptor 6 or 1. J Biol Chem 2004;279:16971-16979.

13 Huang S, Rutkowsky JM, Snodgrass RG, Ono-Moore KD, Schneider DA, Newman JW, Adams SH, Hwang DH: Saturated fatty acids activate TLR-mediated proinflammatory signaling pathways. J Lipid Res 2012;53:2002-2013.

14 Håversen L, Danielsson KN, Fogelstrand L, Wiklund O: Induction of proinflammatory cytokines by longchain saturated fatty acids in human macrophages. Atherosclerosis 2009;202:382-393.

-15 Bauernfeind FG, Horvath G, Stutz A, Alnemri ES, MacDonald K, Speert D, Fernandes-Alnemri T, Wu J, Monks BG, Fitzgerald KA, Hornung V, Latz E: Cutting edge: NF-kappaB activating pattern recognition and cytokine receptors license NLRP3 inflammasome activation by regulating NLRP3 expression. J Immunol 2009;183:787-791.

16 Schroder K, Tschopp J: The inflammasomes. Cell 2010;140:821-832.

17 Zheng D, Dong S, Li T, Yang F, Yu X, Wu J, Zhong X, Zhao Y, Wang L, Xu C, Lu F, Zhang W: Exogenous hydrogen sulfide attenuates cardiac fibrosis through reactive oxygen species signal pathways in experimental diabetes mellitus models. Cell Physiol Biochem 2015;36:917-929.

18 Wallace JL: Physiological and pathophysiological roles of hydrogen sulfide in the gastrointestinal tract. Antiox Redox Signal 2010;12:1125-1133.

19 Wang R. Hydrogen sulfide: a new EDRF. Kidney Int 2009;76:700-704.

20 Whiteman MaW P: Hydrogen sulfide and inflammation: the good, the bad, the ugly and the promising. Exp Rev Clin Pharmacol 2011;4:13-32.

21 Zanardo RC, Brancaleone V, Distrutti E, Fiorucci S, Cirino G, Wallace JL: Hydrogen sulfide is an endogenous modulator of leukocyte-mediated inflammation. Faseb J 2006;20:2118-2120.

22 Wallace JL, Vong L, McKnight W, Dicay M, Martin GR: Endogenous and exogenous hydrogen sulfide promotes resolution of colitis in rats. Gastroenterol 2009;137;569-578, 578 e561.

-23 Zhao Y, Bhushan S, Yang C, Otsuka H, Stein JD, Pacheco A, Peng B, Devarie-Baez NO, Aguilar HC, Lefer DJ, Xian M: Controllable hydrogen sulfide donors and their activity against myocardial Ischemia-Reperfusion injury. ACS Chem Biol 2013;8:1283-1290.

-24 Xu W, Wu W, Chen J, Guo R, Lin J, Liao X, Feng J: Exogenous hydrogen sulfide protects H9c2 cardiac cells against high glucose-induced injury by inhibiting the activities of the p38 MAPK and ERK1/2 pathways. Int J Mol Med 2013;32:917-925.

-25 Yang C, Yang Z, Zhang M, Dong Q, Wang X, Lan A, Zeng F, Chen P, Wang C, Feng J: Hydrogen sulfide protects against chemical Hypoxia-Induced cytotoxicity and inflammation in HaCaT cells through inhibition of ROS/ NF-кB/COX-2 pathway. PLoS ONE 2011;6:e21971.

-26 Zhang HX, Liu SJ, Tang XL, Duan GL, Ni X, Zhu XY, Liu YJ, Wang CN: H2S Attenuates LPS-Induced Acute Lung Injury by Reducing Oxidative/Nitrative Stress and Inflammation. Cell Physiol Biochem 2016;40:1603-1612.

27 Huang Z, Zhuang X, Xie C, Hu X, Dong X, Guo Y, Li S, Liao X: Exogenous Hydrogen Sulfide Attenuates High Glucose-Induced Cardiotoxicity by Inhibiting NLRP3 Inflammasome Activation by Suppressing TLR4/NFкB Pathway in H9c2 Cells. Cell Physiol Biochem 2016;40:1578-1590.

-28 Liu Y, Liao S, Quan H, Lin Y, Li J, Yang Q: Involvement of microRNA-135a-5p in the Protective Effects of Hydrogen Sulfide Against Parkinson's Disease. Cell Physiol Biochem 2016;40:18-26. 


\section{Cellular Physiology Cell Physiol Biochem 2017;42:1635-1644 \begin{tabular}{l|l} 
DOI: 10.1159/000479405 & $\begin{array}{l}\text { O 2017 The Author(s). Published by S. Karger AG, Basel } \\
\text { www.karger.com/cpb }\end{array}$
\end{tabular} \\ Luo et al.: $\mathrm{H}_{2} \mathrm{~S}$ in Fatty Acids Induced Inflammation}

29 Xiao J, Zhu X, Kang B, Xu J, Wu L, Hong J, Zhang Y, Ni X, Wang Z: Hydrogen Sulfide Attenuates Myocardial Hypoxia-Reoxygenation Injury by Inhibiting Autophagy via mTOR Activation. Cell Physiol Biochem 2015;37:2444-53.

-30 Yu Q, Lu Z, Tao L, Yang L, Guo Y, Yang Y, Sun X, Ding Q: ROS-Dependent Neuroprotective Effects of NaHS in Ischemia Brain Injury Involves the PARP/AIF Pathway. Cell Physiol Biochem 2015;36:1539-51.

- 31 Wei X, Zhang B, Zhang Y, Li H, Cheng L, Zhao X, Yin J, Wang G: Hydrogen Sulfide Inhalation Improves Neurological Outcome via NF-кB-Mediated Inflammatory Pathway in a Rat Model of Cardiac Arrest and Resuscitation. Cell Physiol Biochem 2015;36:1527-38.

-32 Wen H, Gris D, Lei Y, Jha S, Zhang L, Huang MT, Brickey WJ, Ting JP: Fatty acid-induced NLRP3-ASC inflammasome activation interferes with insulin signaling. Nat Immunol 2011;12:408-15.

33 Moon JS, Lee S, Park MA, Siempos II, Haslip M, Lee PJ, Yun M, Kim CK, Howrylak J, Ryter SW, Nakahira K, Choi AM: UCP2-induced fatty acid synthase promotes NLRP3 inflammasome activation during sepsis. J Clin Invest 2015;125:665-680.

34 Legrand-Poels S, Esser N, L'homme L, Scheen A, Paquot N, Piette J: Free fatty acids as modulators of the NLRP3 inflammasome in obesity/type 2 diabetes. Biochem Pharmacol 2014;92:131-141.

-35 Dasu MR, Devaraj S, Zhao L, Hwang DH, Jialal I: High glucose induces toll-like receptor expression in human monocytes: Mechanism of activation. Diabetes 2008;57:3090-3098.

-36 Qiao Y, Wang P, Qi J, Zhang L, Gao C: TLR-induced NF-kappaB activation regulates NLRP3 expression in murine macrophages. Febs Lett 2012;586:1022-1026.

-37 Grishman EK, White PC, Savani RC: Toll-like receptors, the NLRP3 inflammasome, and interleukin-1beta in the development and progression of type 1 diabetes. Pediatr Res 2012;71:626-632. 